\title{
How Indian CPI and Industrial Production Respond to Global Oil Price Shocks? Regime-Dependent Impulse Responses
}

\author{
Amanjot Singh, Rajdeep Singh \\ Punjabi University, Patiala, India \\ Email: amanjot_42@yahoo.com
}

How to cite this paper: Singh, A. and Singh, R. (2017) How Indian CPI and Industrial Production Respond to Global Oil Price Shocks? Regime-Dependent Impulse Responses. Theoretical Economics Letters, 7, 1511-1531.

https://doi.org/10.4236/tel.2017.75102

Received: July 23, 2017

Accepted: August 19, 2017

Published: August 22, 2017

Copyright (c) 2017 by authors and Scientific Research Publishing Inc. This work is licensed under the Creative Commons Attribution International License (CC BY 4.0).

http://creativecommons.org/licenses/by/4.0/

\begin{abstract}
For emerging markets like India, where around 80 percent of the crude requirements are met through imports, it is an imperative task to comprehend impact of global crude oil price shocks on Indian macroeconomic variables. The present study attempts to understand these asymmetric dynamic interactions between global crude oil price shocks and Indian macroeconomic variables by employing Markov switching-Vector Autoregressive (MS-VAR) regime-dependent impulse responses in level forms. The findings hold an important place in the wake of inflation targeting regime adopted by the monetary policy authorities. The findings highlight the existence of two regimes, namely lower and higher oil price variance regimes. The response of industrial production and consumer prices is different towards oil price shocks in different regimes. In the lower oil variance regime, there is negative (positive) relationship observed between crude oil shocks and industrial production (consumer prices). On the other hand, there is a positive equilibrium shift in the industrial production in the higher oil variance regime with cost pushing inflationary pressures in the long run. The findings bear strong implication for the policy makers in their attempt to combat effects of crude oil shocks. As per the findings, the emerging market policy makers should display a cautious approach during higher oil price volatile phases in order to support industrial production and consumer demand.
\end{abstract}

\section{Keywords}

Crude Oil, CPI, IIP, India, Regime Switches, VAR Model

\section{Introduction}

As an imperative part of an economic system, crude oil price shocks have a significant impact on the macroeconomic fluctuations. The effect of oil price 
shocks on the macroeconomic variables like inflation and the level of economic activity have attracted much interest from the practitioners, policymakers and the academic fraternity since the first OPEC oil embargo in 1973. The oil price shocks in the 1970s have been accounted as the major reasons for the slowdown in the global economy, especially the oil importing countries (Hamilton [1] [2] [3]). Since 1970s oil prices are subject to several structural changes on account of demand and supply side shocks. The seminal paper by Hamilton [1] motivated other researchers to study the relationship between oil prices and the macroeconomic variables. Studies by Brown and Yücel [4], Kilian [5] and Hamilton [6] focused on the impact of oil price increases on the economic activity. More recently, a curvilinear relationship between oil price and economic activity was reported by Elder and Serletis [7] and Jo [8]. Since last two decades, the international crude oil has exhibited abnormally higher price volatility that can be attributed to geo-political tensions, supply side constraints and ever increasing demand (Kesicki [9]). These uncertain deviations in the world crude oil prices since 1999 have renewed and reinvigorated the interests of the policymakers worldwide to study the impact of oil price shocks on the macroeconomic variables like inflation and economic activity in a regime switching scenario.

Theoretically, there are multiple channels through which oil shocks have an impact on the inflation and the level of economic activity. Since oil serves as the input for majority of the sectors, an increase in the oil price may lead to a subsequent increase in production costs which negatively impacts productivity and the aggregate supply (Brown and Yucel [4]). Also it will lead to a wage-price spiral which will engender to a further increase in the final consumer price levels in an economy. Mork [10] emphasized that these increased price levels in the economy will lead to a decline in the aggregate demand due to the real balance effects. Lardicand Mignon [11] attributed this decline in aggregate demand to the consumption and investment effects. Oil shocks may have an impact on the inflation through exchange rates as well (Hanson et al. [12]). However, the magnitude and direction of such an impact will depend upon whether the country is oil-importing or oil exporting. Taking into consideration these transmission channels, it seems that studying the effect of oil shocks on inflation and economic activity for an oil importing country like India is an empirical issue, the understanding of which will help the policy makers to ensure macroeconomic stability in the country.

The importance of primary energy sources like crude oil for an emerging oil importing country like India is beyond any doubt. India ranks third, with 5.3\% global share in 2015, in terms of primary energy consumption after China and USA. India relies heavily on crude oil as a source of primary energy supply. Crude oil takes a second spot after coal as a source of primary energy supply in India. The total primary energy consumption from crude oil in India is $27.91 \%$ of the total energy consumption. The wide gap between the demand and supply of crude oil in the country is met through imports (see Figure 1). The total import of crude oil in India in calendar year 2015 was 195.1 million tons. The ra- 


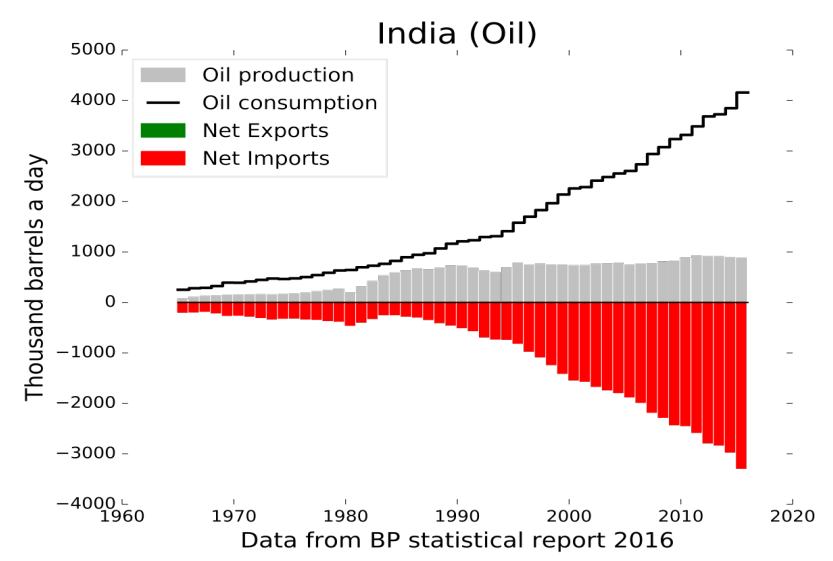

Figure 1. India's reliance on oil.

pidly increasing import bill reached 144.29 billion US\$ in 2012-13. However as per the latest data by Ministry of Petroleum, Government of India, India imported 202.1 million tons of crude oil for 64 billion US\$ in the fiscal year 201516. The decreased import bill is on account of free fall in crude prices since 2014. Such volatility in international crude oil prices and India's huge dependence on it has forced the policymakers to ponder on modeling the relationships of oil price shocks on inflation and economic activity in the country.

A major challenge in macroeconomics time series modeling is to incorporate regime shifts in dynamic interactions (Granger [13]). Perron [14] also highlights the need to consider regime shifts in econometric modeling. Therefore, this study has used the Markov Switching-Vector Autoregressive (MS-VAR) model and regime-dependent impulse response functions taking variables in their level forms. Our basic premise is to capture permanent effects (long run) of fundamental disturbances by taking variables in level forms across the sample period. The Markov regime switching model has been successfully used by many researchers (Hamilton and Susmel [15]; Krolzig [16]; Clements and Krolzig [17]; Singh \& Singh [18]) to study the nonlinear relationships among varied economic variables in a regime switching environment. The present study has used Markov regime switching model due to the following reasons: firstly, the model helps us to identify the variations in the dynamic interactions among the variables. This becomes possible because the model allows us to incorporate regime switches; secondly, impulse responses are generated across different regimes along with the probabilities for the existence of respective regimes; lastly, it allows us to make inferences regarding the regime shifting dates and the events that led to such shifts.

The current study is a unique addition to the sparse literature on emerging oil importing countries in three aspects. Firstly, to the best of our knowledge, no study has explored the dynamic interactions between the oil price shocks and inflation and economic activity for a highly energy dependent emerging Indian economy. Secondly, the current study has used the MS approach which allows us to incorporate regime switches to capture variations in the dynamic interactions among oil prices and inflation and economic activity. The sample period con- 
tains several influential events occurred during the length. Lastly, looking at the geographical coverage of the previous work, most of the studies in this area have been done for developed countries while ignoring the developing countries. This study will be the first of its kind for an emerging economy and the results of which can be generalized for other oil importing emerging economies that have a similar macroeconomic environment like India. The rest of the paper is organized as follows: Section 2 comprises a brief theoretical background of the relationship between oil price shocks and inflation and level of economic activity. Data description and the research methodology part have been discussed in the 3rd section followed by empirical findings and discussion in the 4th section. Finally Section 5 concludes the paper.

\section{Literature Review}

Notwithstanding, a substantial body of literature exists that discusses the relationship between oil price shocks and its effects on inflation and economic activity in a country but still a consensus could not be achieved in this regard. For instance, Hamilton [1], Burbridge and Harrison [19], Loungani [20], Gisser and Goodwin [21], Mork [22], Hamilton [2], Rotemberg and Woodford [23], Hamilton [3], Cunado and Garcia [24] and [25] Bachmeier, Gregorio et al. [26], Zhang and Reed [27], Chen [28] etc. are some of the studies that have tried to capture the dynamic interactions between oil price shocks, inflation and economic activity in a country but with no consensus building in their approach as well as findings. The mixed findings of these studies can be attributed to factors like the countries undertaken in the study, data coverage, research techniques employed and the nature of the data used.

The pioneer study in this area was by Hamilton [1] who considered US data from the period 1948-1980 and used Sim's [29] VAR approach. The author reported a strong correlation between the international oil prices and the Gross National Product of USA and suggested that variations in the crude oil prices was one of the major reasons for recessions in the US post world war II. This linear model advocated by Hamilton [1] was later on extended to incorporate non-linear modeling by Mork [22] who advocated that the asymmetric responses of oil price shocks should be considered by classifying the variation in oil price as upward or downward. Following the seminal work of Hamilton [1], Burbridge and Harrison [19] assessed the dynamic interactions of oil price shocks, industrial production and inflation in five developed countries (USA, Japan, Germany, Canada and United Kingdom). The authors used a Vector Autoregressive (VAR) framework with seven variables and evidenced a major influence of oil prices on industrial production and inflation for USA and Canada and only limited influence in respect of other three countries. Similarly the study undertaken by LeBlanc and Chinn [30] for five developed countries (USA, UK, Germany, France and Japan) evidenced only a moderate impact of oil prices on inflation. Gisser and Godwin [21] used St. Louis type equations to study the nexus between oil prices and macroeconomic variables in the USA from 1962- 
1982. The authors suggested that the oil prices had a vital impact on different macroeconomic variables (including inflation). Rotemberg and Woodford [23] revealed that in an imperfect competition environment, a $1 \%$ increase in the oil prices leads to a decline in $0.25 \%$ output and $0.09 \%$ in real wages. These findings overlap with the findings of Finn [31] who found that oil price increase has a negative impact on the economic activity in a country irrespective of the market structure.

Post 2000s there have been a section of researchers who have found that the intensity of positive relationship between oil price increase and inflation and economic activity has either declined or even disappeared in certain cases after 1980s. Hooker [32] employed a Philips curve framework to study the oil priceinflation nexus in the USA post 1980. The author reported a decline in the intensity of the positive relationship between oil price increase and inflation. In contrast to the generally held viewpoint that recessions and inflation are caused by an uptrend in oil prices, Barsky and Kilian [33] evidenced that the variations in oil prices do not significantly explain the stagflation in the US. Gregorio et al. [26] in their study comprising of a sample of 34 countries reported a downfall in the intensity of relationship between oil prices and inflation in many of the countries under study. Chen [28] also suggested a similar decline in the oil passthrough effect in his study that included 19 industrialized economies.

Looking at the geographical coverage of the previous work, most of the studies in this area have been done for developed countries while ignoring the developing countries. In the Asian content, only Japan has been the country of focus to study the oil price-inflation-economic activity nexus owing to its developed status. Burbidge and Harrison [19] used the monthly data from 1961-1982 for five developed economies (Japan, USA, UK, Germany and Canada). The author's found a limited influence of oil price shocks on industrial production and inflation in case of Japan. In yet another study Zhang [34] used quarterly data from 1957 to 2006 for Japan and reported the existence of a non-linear relationship between the oil price variations and macroeconomic indicators. Jimenez-Rodriguez and Sanchez [35] reported that oil price shocks led to decreased industrial production and increased inflation rates in case of Japan. Only miniscule studies focus on the other countries of Asia as well. For instance, Abeysinghe [36] undertook a study taking a sample of ten Asian economies (Taiwan, Japan, Indonesia, Thailand, South Korea, Malaysia, Philippines, Hong Kong, Singapore, China,) and USA. The author affirmed the existence of negative impact of oil price shocks for both oil importing and oil exporting countries. Also, Cunado and Gracia [24] who examined six Asian countries (Malaysia, South Korea, Philippines, Singapore, Japan and Thailand) confirmed the existence of a significant relationship between oil prices, CPI and economic activity. In contrast Ran and Voon [37] found an insignificant impact of oil prices on economic activity while examining four Asian economies (Singapore, Taiwan, Hong Kong and South Korea) for the period 1984-2007. Kapur [38] focused on modeling and forecasting inflation in India using an augmented Phillips curve framework. The 
results highlight substantial impact of global commodity inflation on non-food manufactured products (NFMP) inflation in India. More recently, Mohanty and John [39] attempted to identify various determinants of inflation in India using a multivariate econometric framework, i.e. structural vector auto regression (SVAR) model. The analysis of identified determinants like crude oil prices, output gap, fiscal policy and monetary policy depict that inflation dynamics in India have changed over time with different determinants showing dynamic variations in the recent years. On these analogies, the present study attempts to capture these asymmetric non-linear relationships between crude shocks and other macroeconomic variables in the Indian economy context.

\section{Empirical Framework}

We employ industrial production index (capacity utilization/economic activity proxy) and consumer price index values relating to the Indian economy with effect from January 1980 to September 2016 on monthly basis. In order to gather response of these latter indices toward global crude oil shocks, global monthly prices of Brent crude oil are used in the study. The values represent the benchmark prices representing the global market. They are determined by the largest exporter and are period averages in nominal US\$ terms. Data relating to monthly indices are collected from International Monetary Fund's (IMF's) and Fred's economic databases. All the indices are not adjusted for seasonal variations across the years in the wake of employment of regime switches and maintenance of sensitivity in the undertaken indices thereon. A conventional Vector Autoregressive (VAR) model with structural shocks can certainly capture response of the latter economic indices toward global crude shocks, yet the model fails to allow for flexibility with respect to structural changes in the crude prices. Therefore, the present study employs regime-dependent structural impulse responses under the Markov regime switching VAR approach.

\subsection{Markov Switching-Vector Autoregressive Model (MS-VAR Model)}

Several attempts have been made in the past to account for impact of crude shocks on macroeconomic variables, like GDP growth rates, employment or output levels, etc. (Hamilton [1]; Mork [22]; Davis \& Haltiwanger [40]; Hamilton \& Herrera [41]; Hooker [32]; Ehrmann et al. [42]; Balcilar et al. [43] and so on). Conventionally, macroeconomic studies must consider regime shifts or structural changes in the movement of variables (Granger [13]). The Markov Switching (MS) approach proposed by Hamilton [44] provides a flexible non-linear solution to this perspective, wherein the model captures regime changing behavior of the undertaken variables. The global oil prices are subject to several jumps or business cycle variations. So, MS approach acts as a reasonable approach capturing response of the macroeconomic variables toward structural oil price adjustments. In this approach, changes in regimes are governed by random exogenous events and probabilities are estimated for the existence of 
respective regimes. This ensures time-varying behavior of the undertaken variables toward structural adjustments. Krolzig [45] extended univariate version of MS approach to multivariate in the context of MS-VAR model. However, since our objective is to gather regime-dependent impulse responses, we employ Ehrmann et al. [42] approach, whereby the model helps in conducting comparisons across impulse responses in different regimes without assuming existence of cointegration vectors among the variables. As long as the regimes are persistent with reasonable time horizon, impulse responses are valid and a useful analytical tool to gather response of the respective macroeconomic variables towards global oil shocks.

Equation (1) describes the model with its statistical contours for a small VAR. The $K$ endogenous variables $X_{t}$ are explained by an intercept $v_{i}$, autoregressive terms equivalent to order $p$ and a residual $A_{i} u_{t}$. Hence, all the parameters are allowed to switch across regimes so that each of the $m$ regimes are identified by an intercept $v_{i}$, autoregressive terms $B_{1, i}, \cdots, B_{p, i}$ and a matrix $A_{i}$.

$$
\begin{gathered}
X_{t}=\left\{\begin{array}{cl}
v_{1}+B_{11} X_{t-1}+\cdots+B_{p 1} X_{t-p}+A_{1} u_{t} & \text { if } S_{t}=1 \\
v_{m}+B_{1 m} X_{t-1}+\cdots+B_{p m} X_{t-p}+A_{m} u_{t} & \text { if } S_{t}=m
\end{array}\right. \\
u_{t} \sim N\left(0 ; I_{K}\right)
\end{gathered}
$$

where $u_{t}$ is a $K$-dimensional vector of residuals (fundamental disturbances) assumed to be normally distributed and serially uncorrelated. The variance of each fundamental disturbance is normalized to unity in order to have identity variance-covariance matrix. However, these fundamental disturbances are premultiplied by a regime-dependent matrix $A_{i}$ in order to have a regime-dependent variance-covariance matrix $\Sigma_{i}$ of the residuals $A_{i} u_{t}$.

$$
\Sigma_{i}=E\left(A_{i} u_{t} u_{t}^{\prime} A_{i}^{\prime}\right)=A_{i} E\left(u_{t} u_{t}^{\prime}\right) A_{i}^{\prime}=A_{i} I_{K} A_{i}^{\prime}=A_{i} A_{i}^{\prime}
$$

In MS approach, the regime $S_{t}$ is assumed to follow a hidden $m$-state Markov chain, whereby the probability of remaining in regimes is assumed to be exogenous and constant. Equation (3) describes conditional probabilities in an exogenous transition matrix $P$ framework:

$$
\begin{gathered}
\operatorname{Pr}\left(s_{t+1}=j \mid s_{t=i}\right)=p_{i j} \\
P=\left[\begin{array}{cccc}
p_{11} & p_{12} & \cdots & p_{1 m} \\
p_{21} & p_{22} & \cdots & p_{2 m} \\
\vdots & \vdots & \ddots & \vdots \\
p_{m 1} & p_{m 2} & \cdots & p_{m m}
\end{array}\right]
\end{gathered}
$$

In an $m$-state model, there are $m \times m$ conditional transition probabilities. These transition probabilities highlight switching behavior of the macroeconomic variables in different regimes across $t$ time.

\subsubsection{Estimation}

Since MS approach involves joint estimation of all the parameters and the hidden Markov chain, the likelihood function tends to follow a recursive nature. Under these conditions, the model can however be estimated by applying the Expecta- 
tions-Maximization algorithm (Hamilton [44] and Krolzig [45]). The first expectations step conjectures the hidden Markov chain for a given set of parameters and the second step maximization re-estimates the parameters for the inferred Markov chain until the convergence is achieved. The algorithm estimates parameters associated with each regime, the transition probability matrix and an optimal inference of the hidden Markov chain followed by the regime or in simpler terms, smooth probabilities for the existence of respective regimes. As the primary objective of the study is to derive relationship between endogenous variables and fundamental disturbances across different regimes, the identification problem relating to structural shocks arises. The EM algorithm gives estimates of only variance-covariance matrix $\Sigma_{1}, \cdots, \Sigma_{m}$ and not the matrices $A_{1}, \cdots, A_{m}$. In order to identify it, some restrictions are to be imposed on the unrestricted parameter estimates (Sims [29]). Each matrix $A_{i}$ has $K^{2}$ elements to be identified, so $K^{2}$ restrictions are to be imposed. However, the identity $A_{i} A_{i}^{\prime}=\Sigma_{i}$ from Equation (2) imposes $K(K+1) / 2$ restrictions because of the symmetry of variance-covariance matrix leaving $K(K-1) / 2$ missing restrictions. The endogenous variables are ordered on the pretext that the fundamental disturbances have a contemporaneous impact on the first variable itself and variables ranked below it. It can be generated from a Choleski decomposition of matrix leaving matrix $A_{i}$ lower triangular and exactly identified. In the present study, variables are ordered as industrial production, consumer price index and global crude oil prices as a recursive structure for the model. It is based on the assumption that global crude prices react more instantaneously at the arrival of any news (liquidity in commodity markets) as compared to other variables (Ehrmann et al. [42]).

\subsubsection{Regime-Dependent Impulse Response Functions}

Conventional impulse responses highlight expected changes (responses) in the endogenous variables on account of one standard deviation shock to one of the residuals. In MS approach, regime-dependent impulse responses are conditional on a given regime at the time of disturbance and expected duration of the regime. There are around $m K^{2}$ regime-dependent impulse response functions corresponding to $K$ endogenous variables reacting to $K$ disturbances in $m$ regimes. Equation (4) describes regime-dependent impulse response functions for regime $i$. It identifies expected changes in endogenous variables at time $t+h$ to a one standard deviation shock to the $k$-th fundamental disturbance at time $t$, conditional on regime $i$.

$$
\left.\frac{\partial E_{t} X_{t+h}}{\partial u_{k, t}}\right|_{s_{t}=\cdots=s_{t+h}=i}=\theta_{k i, h} \quad \text { for } h \geq 0
$$

A series of $K$-dimensional response vectors $\theta_{k i, 1} \cdots, \theta_{k i, h}$ predict the response of the endogenous variables. The estimates of the response vectors are identified by combining unrestricted parameter estimates with the estimate of matrix $A_{i}^{\wedge}$ obtained through identification restrictions. Equations (5) and (6) link estimated response vectors with estimated parameters.

$$
\theta_{k i, 0}^{\wedge}=A_{i}^{\wedge} u_{0}
$$




$$
\theta_{k i, h}^{\wedge}=\sum_{j=1}^{\min (h, p)} B_{j i}^{\wedge-j+1} A_{i}^{\wedge} u_{0} \text { for } h>0
$$

To gauge the precision of the estimated response vectors, standard bootstrapping procedure is employed. It involves creating artificial histories of the model and then employing these histories to the same estimation procedure. So, the confidence intervals are computed on the basis of 1000 bootstrap replications. It is pertinent to mention that we employ MS approach under VAR framework without really considering the existence of any cointegration vectors among the variables. It is due to employment of undertaken variables in their level forms thereby maintaining long run (random) interactive structures. We combine regime-dependent impulse response analysis with Markov chain Monte Carlo (MCMC) integration. Therefore, we examine response of Indian macroeconomic variables to global oil price shocks assuming a given state of regime, i.e. higher or lower oil variance regimes. We estimate the MS-VAR model using MCMC method with Gibbs sampling. The MCMC estimates employ 2000 burn-in and 5000 posterior draws.

\section{Empirical Findings and Discussion}

Table 1 summarizes descriptive statistics of the respective variables. All the variables are undertaken in their logarithmic terms for the purpose of ensuring consistency across them. On an average, Indian consumer price index is found to be higher as compared to the others coupled with higher level of variations as well. Both CPI and industrial production indices are negatively skewed with greater probability of decreasing consumer prices and industrial output. Whereas on the other hand, the global crude oil index registers greater probability of increasing oil prices on account of positive skewness value. The kurtosis values are less than 3 with respect to all the indices indicating that the distribution is platykurtic producing fewer extreme outliers.

Table 1. Descriptive statistics.

\begin{tabular}{cccc}
\hline Descriptive & LOGCPI & LOGIP & LOGCRUDE \\
\hline Mean & 3.7408 & 3.7395 & 3.5174 \\
Median & 3.8664 & 3.7398 & 3.4008 \\
Maximum & 5.0577 & 4.8081 & 4.8973 \\
Minimum & 2.2548 & 2.4996 & 2.4256 \\
Sigma & 0.7875 & 0.6761 & 0.6139 \\
Skewness & -0.1263 & -0.0819 & 0.4822 \\
Kurtosis & 1.9101 & 1.7844 & 2.0841 \\
Jarque-Bera & 22.9994 & 27.6449 & 32.5061 \\
Probability & 0.0000 & 0.0000 & 0.0000 \\
Observations & 441 & 441 & 441 \\
\hline
\end{tabular}

Source: Computed by the authors. 
Moreover, the Jarque-Bera test also highlights non-normal distribution of the respective indices because the probability values fail to accept null hypothesis of normal distribution. The total number of monthly observations is 441 . Under conventional literature, stationarity of the variables play a pivotal role in analyzing dynamic interactions among the undertaken variables. However, in the present study, we attempt to capture these dynamic interactions without really disturbing information contents in the underlying variables. So, the MS-VAR model is estimated with levels. Non-stationarity in data does not pose any problem in estimation since the residuals behave quite reasonably (Sims et al. [46]). Moreover, our ultimate endeavor is to gather impulse responses via MCMC approach instead of estimated parameters, hence leveled indices act as a reasonable source to capture informed relationships.

Further, Table 2 reports conventional linear VAR model results. The findings suggest significant impact of the global crude oil prices on the Indian consumer prices and industrial production. On the contrary, global oil prices are not significantly influenced by any of these variables at the 5 percent significance level. Figure 2 is the graphical presentation of the residuals derived from linear VAR model. These time-varying movements of the residuals can be compared with residuals derived from MS-VAR approach in order to ensure adequacy of the latter model.

IP

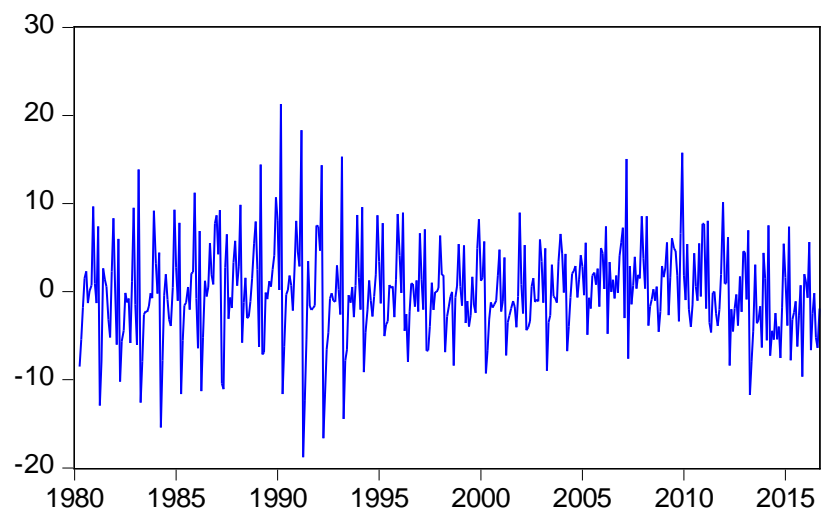

CPI

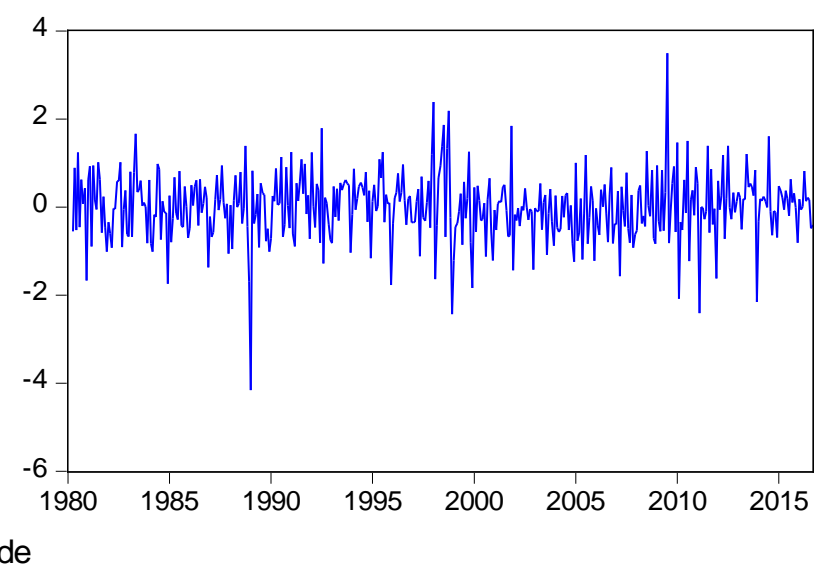

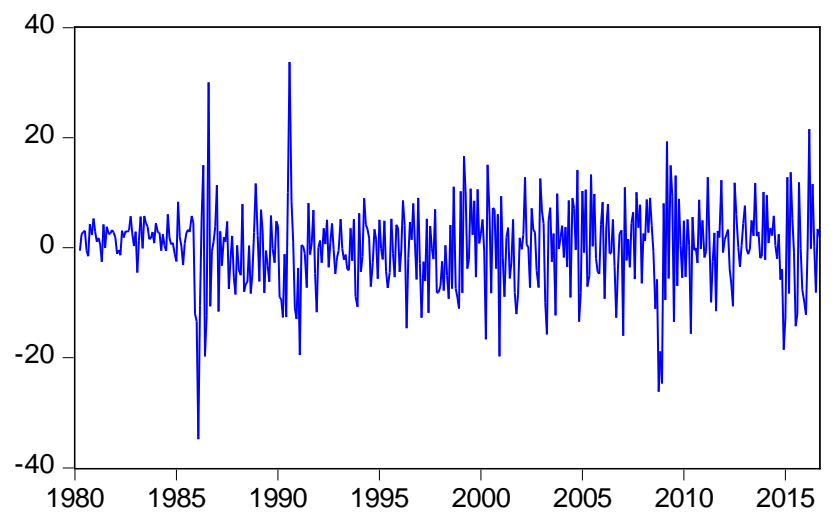

Figure 2. Linear VAR model (Residuals). Source: Computed by the authors. 
Table 2. Linear VAR model.

\begin{tabular}{|c|c|c|c|}
\hline Parameters & LOGIP & LOGCPI & LOGCRUDE \\
\hline \multirow[t]{3}{*}{$\operatorname{LOGIP}(-1)$} & $0.368793^{*}$ & $-0.014232^{\star}$ & 0.093859 \\
\hline & $(0.04883)$ & $(0.00691)$ & $(0.06954)$ \\
\hline & [7.55252] & {$[-2.05838]$} & [1.34967] \\
\hline \multirow{3}{*}{ LOGIP $(-2)$} & $0.339681^{\star}$ & -0.004732 & 0.034678 \\
\hline & $(0.04893)$ & $(0.00693)$ & $(0.06969)$ \\
\hline & [6.94179] & {$[-0.68297]$} & {$[0.49762]$} \\
\hline \multirow[t]{3}{*}{$\operatorname{LOGIP}(-3)$} & $0.136242^{*}$ & $0.030288^{*}$ & 0.047192 \\
\hline & $(0.04760)$ & $(0.00674)$ & $(0.06779)$ \\
\hline & [2.86230] & [4.49405] & {$[0.69616]$} \\
\hline \multirow[t]{3}{*}{ LOGCPI (-1) } & $-1.307099^{\star}$ & $1.344939^{\star}$ & -0.310449 \\
\hline & $(0.34254)$ & $(0.04850)$ & $(0.48783)$ \\
\hline & {$[-3.81594]$} & [27.7302] & {$[-0.63639]$} \\
\hline \multirow[t]{3}{*}{ LOGCPI (-2) } & $2.480915^{\star}$ & $-0.392053^{\star}$ & 0.467690 \\
\hline & $(0.55870)$ & $(0.07911)$ & $(0.79568)$ \\
\hline & [4.44053] & [-4.95592] & [0.58779] \\
\hline \multirow[t]{3}{*}{ LOGCPI (-3) } & $-1.049779^{*}$ & 0.036745 & -0.286635 \\
\hline & $(0.34255)$ & $(0.04850)$ & $(0.48785)$ \\
\hline & {$[-3.06460]$} & [0.75758] & {$[-0.58755]$} \\
\hline \multirow[t]{3}{*}{ LOGCRUDE $(-1)$} & $-0.093821^{\star}$ & 0.002861 & $1.282626^{\star}$ \\
\hline & $(0.03389)$ & $(0.00480)$ & $(0.04827)$ \\
\hline & {$[-2.76834]$} & [0.59619] & [26.5743] \\
\hline \multirow[t]{3}{*}{ LOGCRUDE $(-2)$} & $0.153661^{\star}$ & 0.006784 & $-0.337612^{*}$ \\
\hline & $(0.05415)$ & $(0.00767)$ & $(0.07711)$ \\
\hline & [2.83790] & [0.88492] & {$[-4.37816]$} \\
\hline \multirow[t]{3}{*}{ LOGCRUDE $(-3)$} & -0.046016 & $-0.009743^{\star}$ & 0.016796 \\
\hline & $(0.03376)$ & $(0.00478)$ & $(0.04808)$ \\
\hline & {$[-1.36288]$} & {$[-2.03806]$} & {$[0.34930]$} \\
\hline \multirow[t]{3}{*}{$\mathrm{C}$} & $7.821672^{\star}$ & 0.138179 & -3.873747 \\
\hline & $(2.12322)$ & $(0.30063)$ & $(3.02380)$ \\
\hline & [3.68388] & {$[0.45963]$} & [-1.28109] \\
\hline
\end{tabular}

Source: Computed by the authors; Standard errors in ( ) and t-statistics in [ ]; ${ }^{*}$ Significant at $5 \%$ level; Schwarz Information Criteria (SIC) points 4 months lagged values but 3 months are employed considering estimation issues.

It may be noted that VAR model summarizes information contents in the form of estimated parameters, however in practical scenarios impulse responses are carved out in order to generate response of one variable to structural shocks in another across forecasted horizons. So, in order to establish the latter relationships, the present study employs MS approach under VAR framework. Table 3 reports MS-VAR model results as per the EM approach. Here we assume 
Table 3. MS-VAR model results (EM approach).

\begin{tabular}{|c|c|c|c|c|c|c|}
\hline \multirow{2}{*}{ Parameters } & \multicolumn{3}{|c|}{ Regime-1 } & \multicolumn{3}{|c|}{ Regime-2 } \\
\hline & LIP & LCPI & LCRUDE & LIP & LCPI & LCRUDE \\
\hline Constant & $\begin{array}{c}5.5166 \\
(1.0468)\end{array}$ & $\begin{array}{c}0.7514 \\
(1.1803)\end{array}$ & $\begin{array}{c}-6.6376^{\star *} \\
(-1.9560)\end{array}$ & $\begin{array}{l}20.1740^{*} \\
(5.2466)\end{array}$ & $\begin{array}{c}-0.2890 \\
(-0.4268)\end{array}$ & $\begin{array}{l}-31.1812^{\star} \\
(-3.7713)\end{array}$ \\
\hline $\operatorname{LIP}(-1)$ & $\begin{array}{c}0.4008^{*} \\
(4.9269)\end{array}$ & $\begin{array}{c}-0.0202 \\
(-1.3948)\end{array}$ & $\begin{array}{l}0.1482^{\star} \\
(2.0664)\end{array}$ & $\begin{array}{l}0.2098^{\star} \\
(3.0750)\end{array}$ & $\begin{array}{c}-0.0063 \\
(-0.4877)\end{array}$ & $\begin{array}{l}0.2554^{\star *} \\
(1.8153)\end{array}$ \\
\hline $\operatorname{LIP}(-2)$ & $\begin{array}{l}0.3243^{*} \\
(3.8244)\end{array}$ & $\begin{array}{c}-0.0054 \\
(-0.3292)\end{array}$ & $\begin{array}{c}-0.0400 \\
(-0.5565)\end{array}$ & $\begin{array}{l}0.3500^{*} \\
(5.3189)\end{array}$ & $\begin{array}{c}-0.0063 \\
(-0.4725)\end{array}$ & $\begin{array}{l}0.3173^{\star} \\
(2.5012)\end{array}$ \\
\hline $\operatorname{LIP}(-3)$ & $\begin{array}{c}0.1249 \\
(1.0320)\end{array}$ & $\begin{array}{l}0.0282^{* *} \\
(1.8637)\end{array}$ & $\begin{array}{c}0.0189 \\
(0.3201)\end{array}$ & $\begin{array}{l}0.1448^{* *} \\
(1.6493)\end{array}$ & $\begin{array}{l}0.0320^{\star} \\
(2.1466)\end{array}$ & $\begin{array}{c}0.0773 \\
(0.6424)\end{array}$ \\
\hline LCPI $(-1)$ & $\begin{array}{c}-0.4430 \\
(-0.4829)\end{array}$ & $\begin{array}{c}1.3182^{*} \\
(14.2137)\end{array}$ & $\begin{array}{c}0.1176 \\
(0.2981)\end{array}$ & $\begin{array}{l}-2.8363^{*} \\
(-4.9685)\end{array}$ & $\begin{array}{c}1.3491^{\star} \\
(15.6559)\end{array}$ & $\begin{array}{c}-0.6571 \\
(-0.6645)\end{array}$ \\
\hline LCPI $(-2)$ & $\begin{array}{c}1.1222 \\
(0.9209)\end{array}$ & $\begin{array}{c}-0.30538^{\star *} \\
(-1.6844)\end{array}$ & $\begin{array}{c}-0.3436 \\
(-0.5169)\end{array}$ & $\begin{array}{l}4.1608^{\star} \\
(4.8221)\end{array}$ & $\begin{array}{l}-0.4699^{*} \\
(-3.6196)\end{array}$ & $\begin{array}{c}2.5633 \\
(1.4367)\end{array}$ \\
\hline LCPI $(-3)$ & $\begin{array}{c}-0.5568 \\
(-0.9860)\end{array}$ & $\begin{array}{l}-0.01476 \\
(-0.1131)\end{array}$ & $\begin{array}{c}0.1228 \\
(0.2953)\end{array}$ & $\begin{array}{l}-1.1268^{*} \\
(-2.1773)\end{array}$ & $\begin{array}{c}0.1039 \\
(1.4314)\end{array}$ & $\begin{array}{l}-2.3255^{*} \\
(-2.0520)\end{array}$ \\
\hline LCrude $(-1)$ & $\begin{array}{l}-0.2187^{*} \\
(-2.1566)\end{array}$ & $\begin{array}{c}0.0124 \\
(0.9046)\end{array}$ & $\begin{array}{c}1.0568^{\star} \\
(13.3438)\end{array}$ & $\begin{array}{c}-0.0207 \\
(-0.5593)\end{array}$ & $\begin{array}{c}0.0004 \\
(0.0874)\end{array}$ & $\begin{array}{c}1.2126^{*} \\
(16.5083)\end{array}$ \\
\hline LCrude (-2) & $\begin{array}{l}0.2954^{*} \\
(2.1984)\end{array}$ & $\begin{array}{c}0.0109 \\
(0.4889)\end{array}$ & $\begin{array}{c}-0.0378 \\
(-0.3282)\end{array}$ & $\begin{array}{c}0.0844 \\
(1.5460)\end{array}$ & $\begin{array}{c}0.0071 \\
(0.8016)\end{array}$ & $\begin{array}{l}-0.3417^{*} \\
(-2.8975)\end{array}$ \\
\hline LCrude (-3) & $\begin{array}{l}-0.06241 \\
(-0.8096)\end{array}$ & $\begin{array}{l}-0.0246^{\star *} \\
(-1.8882)\end{array}$ & $\begin{array}{c}-0.0252 \\
(-0.3354)\end{array}$ & $\begin{array}{c}-0.0079 \\
(-0.2451)\end{array}$ & $\begin{array}{c}-0.0082 \\
(-1.4333)\end{array}$ & $\begin{array}{c}-0.0395 \\
(-0.5597)\end{array}$ \\
\hline$\sigma^{2}$ & $\begin{array}{l}39.0496^{*} \\
(8.6743)\end{array}$ & $\begin{array}{l}0.7519^{*} \\
(9.6124)\end{array}$ & $\begin{array}{l}17.4338^{*} \\
(6.6906)\end{array}$ & $\begin{array}{l}16.4426^{*} \\
(7.6890)\end{array}$ & $\begin{array}{c}0.3841^{*} \\
(8.8692)\end{array}$ & $\begin{array}{c}75.1675^{*} \\
(10.5718)\end{array}$ \\
\hline$P(1,1)$ & & & $0.9322^{\star}$ & $35.7165)$ & & \\
\hline $\mathrm{P}(1,2)$ & & & $0.0542^{\star}$ & $2.4752)$ & & \\
\hline
\end{tabular}

Source: Computed by the authors; ${ }^{*},{ }^{* *}$ significant at 5 and $10 \%$ levels respectively.

existence of two regimes only in order to ensure parsimonious estimation across regimes. To ensure adequacy of non-linear MS-VAR framework against the linear one, non standard likelihood ratio (LR) test is employed with Davies's [47] upper bound for the significance level of the LR statistic. The likelihood ratio test for the null hypothesis of linearity is statistically significant (LR: 188.64, $p<$ 0.000 ) and this suggests that linearity assumption is strongly rejected.

Regime-1 relates to lower oil variance regime, whereas regime- 2 relates to higher oil variance regime (around four times of lower regime). Whereas, the variances of other macroeconomic variables are observed to be higher in case of regime-1 and lower in case of regime-2. Since our objective is to gather responses of Indian CPI and industrial output to shocks in global oil prices, we denote regime- 1 as lower oil variance regime and regime- 2 as higher oil variance regime (Figure 3).

There are two distinctive regimes, wherein most of the estimated parameters are found to be statistically different from zero at the 5 and 10 percent significance levels. Interestingly, crude oil prices are observed to be having a statistically 
Regime-1

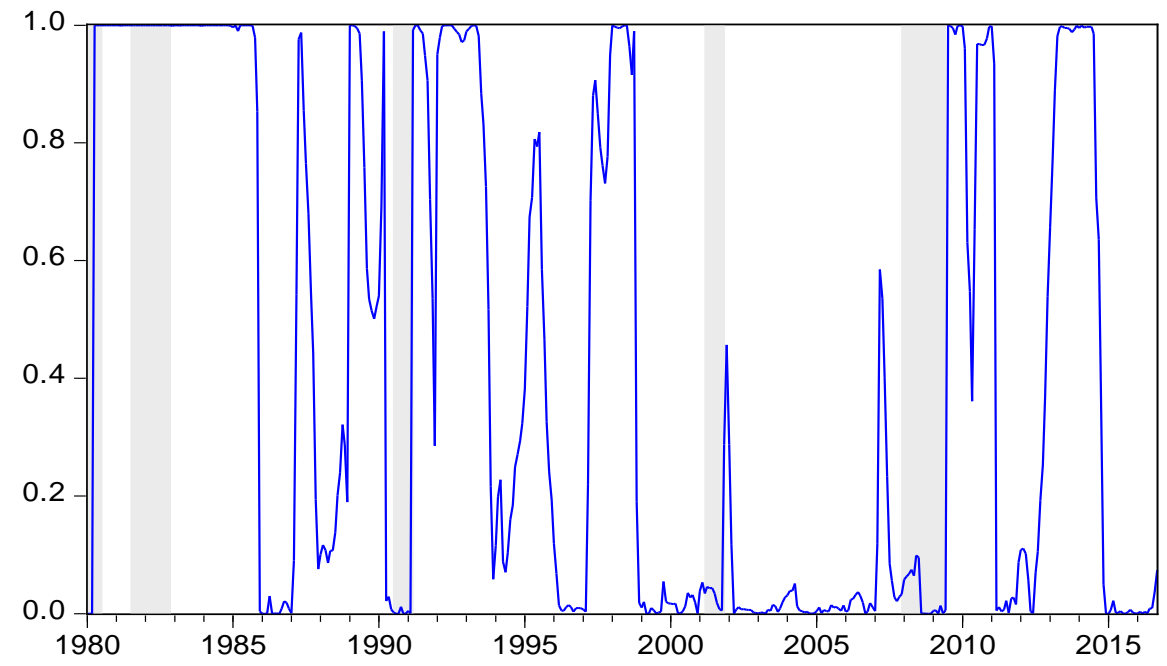

Figure 3. Smoothed probabilities for the existence of Regime-1. Source: Computed by the authors.

significant impact on the Indian consumer prices and industrial output only in the first regime, i.e. during lower oil volatility regime. Whereas on the other hand, oil prices are not found to be statistically influencing consumer prices and industrial output during the higher oil volatility regime. The probability for the existence of regime- 1 (low oil variance) is 0.9322 , whereas the probability for the existence of regime-2 (high oil variance) is 0.9458 . The respective transition probabilities from lower to higher oil variance regime and vice versa are 0.0542 and 0.0678 . Both the regimes are highly persistent with the duration of 14.75 $\left(\frac{1}{1-p_{11}}\right)$ and $18.45\left(\frac{1}{1-p_{22}}\right)$ months for the existence of low and high oil variance regimes respectively. The timings of both the regimes itself indicate that the impulse responses of both the macroeconomic variables will be different. Figure 4 reports smoothed probabilities for the existence of regime-1, lower oil variance regime across the sample period. It indicates that during the US recessionary periods (highlighted portions), the probability remains more or less near to zero depicting a higher volatility in the global oil prices.

Moreover, since early 2015, the global oil prices are in higher volatility regime recording several demand and supply side shocks aftermath the financial crisis. The time-varying movement of probability values report existence of structural changes in dynamic interactions between the undertaken variables across changing regimes. Further, the covariance coefficient between industrial production and crude oil prices comes out to be -1.61 in lower oil variance regime. This indicates inverse movement between crude oil and capacity utilization during lower oil price volatility. On the other hand, the coefficient is positive (4.59) in the higher oil variance regime indicating a positive relationship between the latter indices. A similar kind of relationship is observed between the crude oil prices and consumer prices in both the regimes but the magnitude of negative rela- 
IP

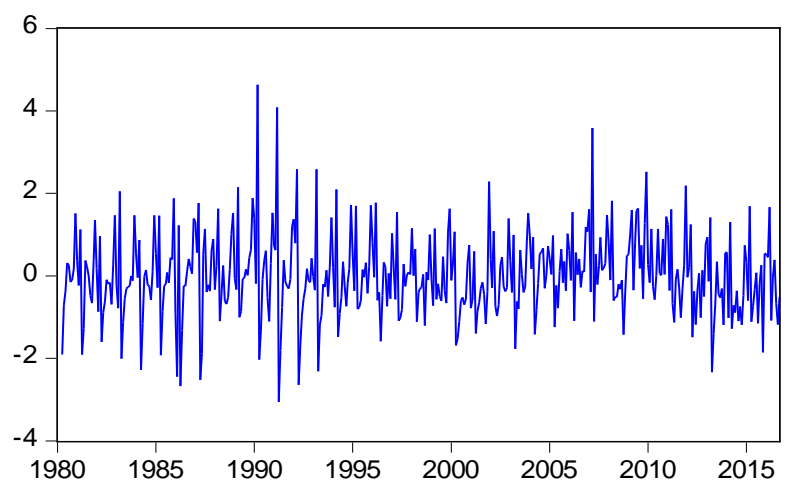

CPI

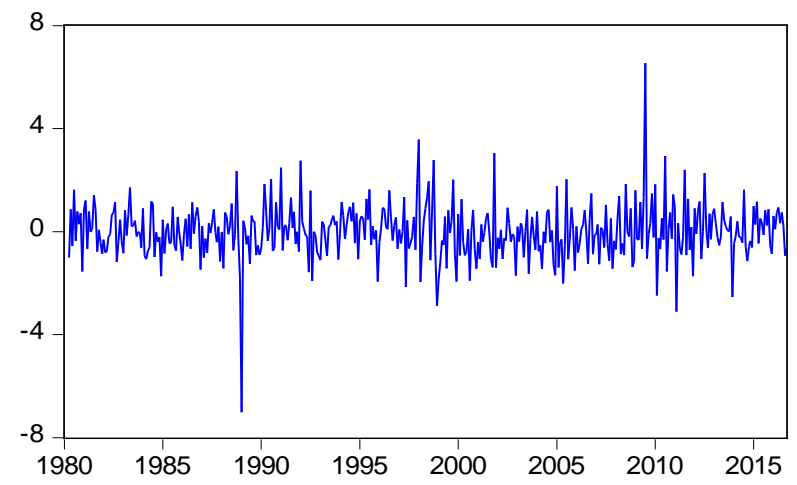

CRUDE

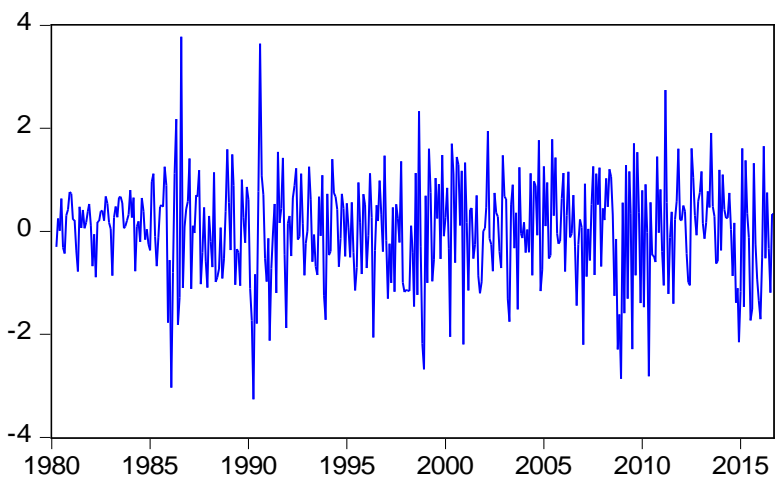

Figure 4. MS-VAR model (Residuals). Source: Computed by the authors.

tionship is observed to be higher in the first regime $(-0.59)$. Figure 4 reports time-varying residuals derived from MS-VAR model estimated via EM approach. The residuals are certainly much more reasonable as compared to conventional linear VAR approach in terms of ARCH effects and normality.

However, it may be noted that standard linear or non-linear VAR estimates may not highlight exact nature of relationship between the underlying variables owing to complications involved in their interpretations. But the latter approach surely sets the stage for generation of asymmetric impulse responses under the endogenous non-linear VAR framework. Figure 5 reports impulse responses under the linear VAR framework. Initially, the response of industrial production is negative on account of oil price shocks but later on it starts expanding after around five months with a permanent shift in its long run behavior. Similarly, the response of consumer prices is positive registering a permanent shift in its long run behavior. It should be noted that the period from 1980 to 2016 comprises several international financial or economic events which may refute the existence of such linear relationship. So, in order to have a greater clarity on the latter relationships, non-linear approach is expected to be employed.

Figure 6 reports impulse response functions across different regimes via MCMC integration approach for 100 following months. In the lower oil variance regime, the response of industrial production (capacity utilization) is negative initially but after around five months, it starts recording gains and achieves equi- 
Response to Cholesky One S.D. Innovations \pm 2 S.E.

Response of LOGIP to LOGCRUDE

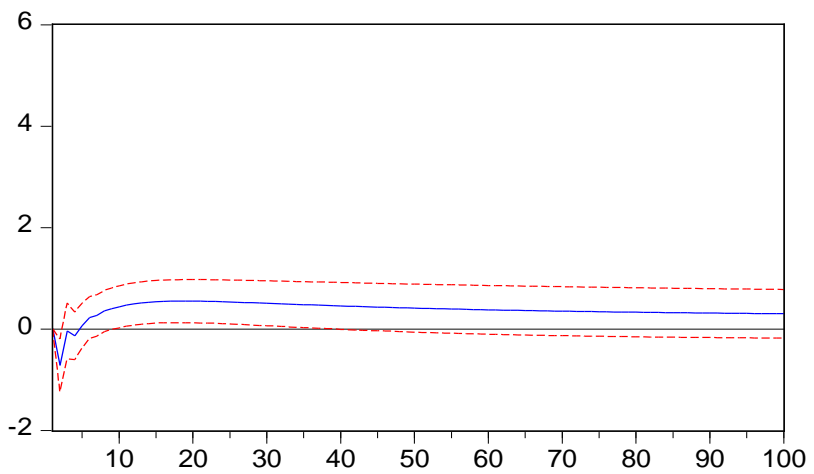

Response of LOGCPI to LOGCRUDE

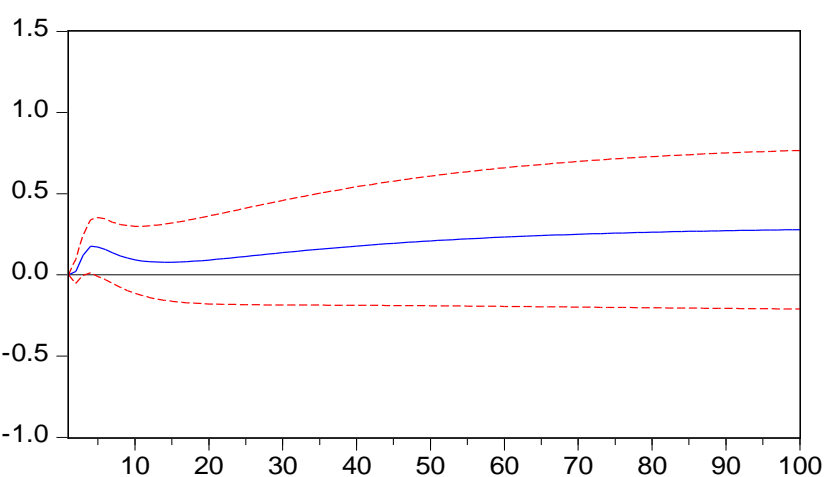

Response of LOGCRUDE to LOGCRUDE

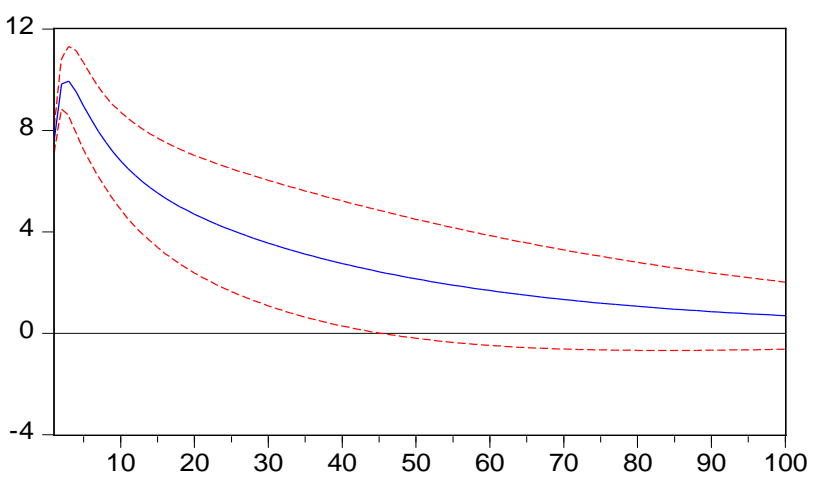

Figure 5. Impulse response functions under linear VAR framework. Source: Computed by the authors.

Regime 1

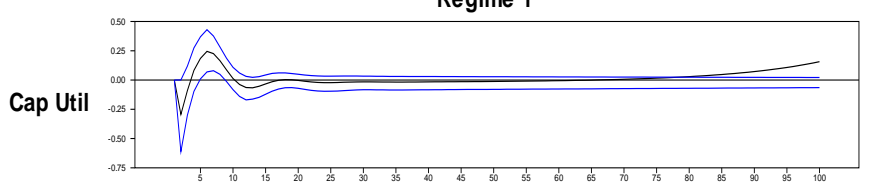

CPI

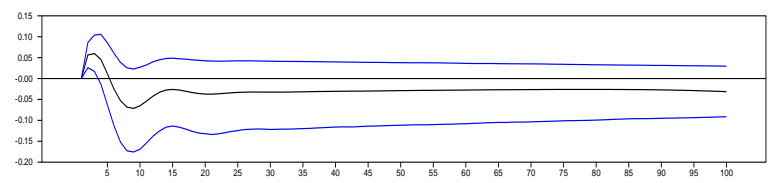

Oil Price

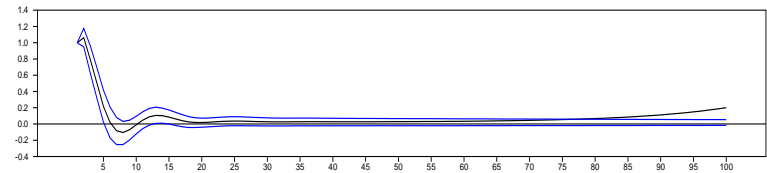

Regime 2
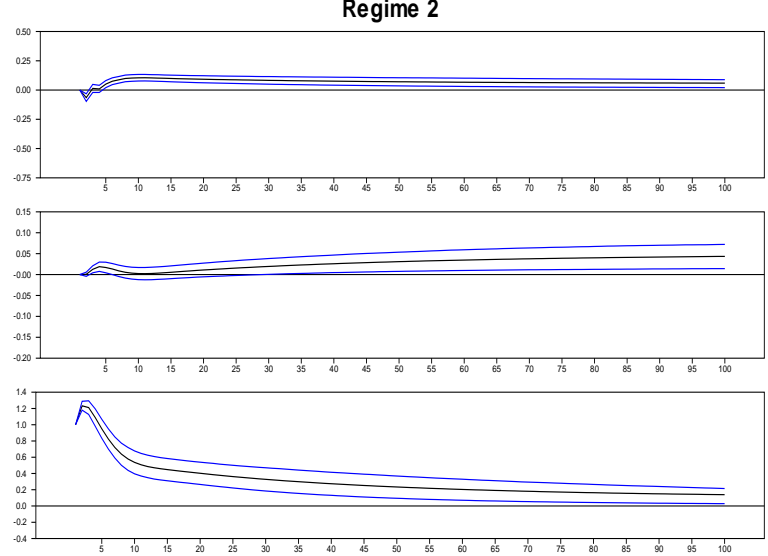

Responses to Oil Shock

Figure 6. Regime-dependent impulse response functions. Source: Computed by the authors.

librium level after around fifteen months. This indicates that during lower oil variance regime (when oil price instability is lower), industrial production decreases but with a reversal of expansionary phase after around five months. A lower volatile oil prices gives greater certainty to the industrial producers to predict future oil prices and plan their production cost targets accordingly. The response of consumer prices is approximately inverse to the industrial production 
in the first regime. Initially, it increases on account of increasing production costs levels and then starts following a downward trend after around five months when the production level starts increasing in the economy. This further supports the phenomenon that the increased producers' prices in the wake of increasing crude oil prices are perhaps passed on to the ultimate consumers. On the other hand, in the higher oil variance regime, the response of industrial production towards oil price shocks is initially negative, despite the fact that it depicts an equilibrium shift (of lesser magnitude as compared to regime-1) in the production levels in the longer run; after around five months. On a similar note, consumer prices also witness an expected increasing trend towards oil price shocks in the long run. It must be remembered that in an emerging market like India, crude oil holds an important place in its energy utilization, yet the contribution of the latter is not that significant that can clearly channelize the production levels of an economy.

For instance, during the lower oil variance regime, the impact of crude oil shocks may be quantified easily but the same becomes an arduous task during the higher oil variance regimes. There are other alternative energy resources also that can be relied upon during this higher variance regime. Moreover, a larger part of the oil prices (sensitive petroleum products) are also financed by the government subsidies and under-recoveries to oil marketing companies (OMCs) (Figure 7) in India. These under-recoveries are shared between the government and OMCs in order to provide these oil based products at subsidized prices to consumers. The intended subsidies are provided keeping oil price movements in consideration in order to support industrial production and consumer prices. The government intends to control inflationary trends in the economy by keeping a check on the cascading inflationary impact of higher freight, raw materials and transportation charges on the prices of essential commodities in India. Another way to look at this positive relationship between the crude prices and industrial production in the higher oil variance regime is that the crude oil prices also have an impact on the exchange rates on account of India's huge dependence on oil imports. The depreciating exchange rates also increase competitive-

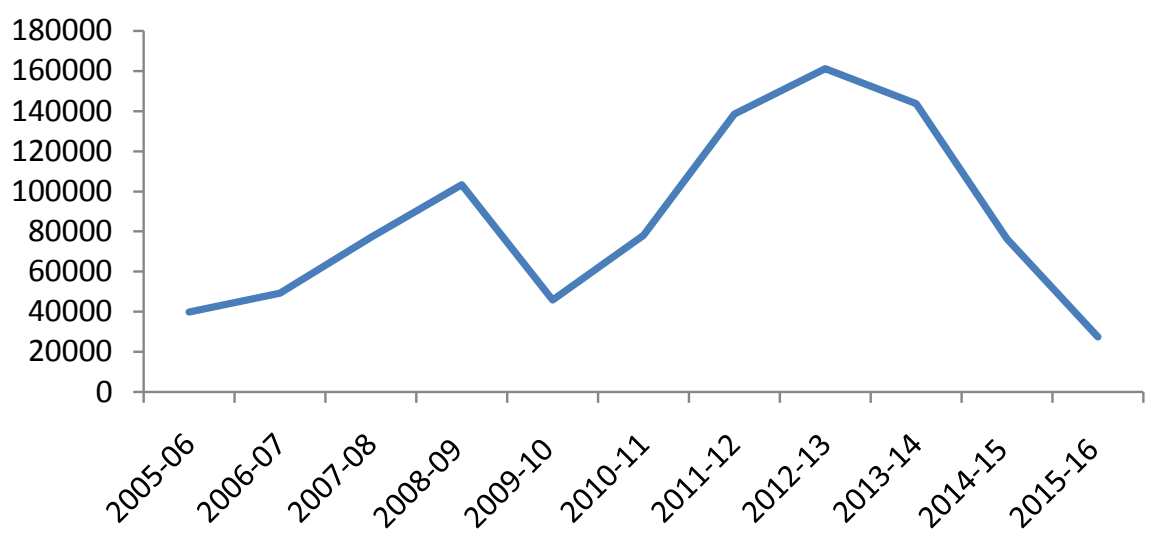

Figure 7. Under-recoveries to oil marketing companies. Source: Ministry of Petroleum and Natural Gas, India; (in Rs. Crores). 
ness of the exports' sectors registering increased production levels in the economy.

In simple terms, there is indeed a negative relationship between crude prices and industrial production initially during the lower oil variance regime because of the ability to predict the future crude prices with much more precision on account of lesser degree of uncertainty; findings are consistent with the several earlier studies in both theoretical as well as empirical senses. A one unit change in oil prices entails to around 0.25 units change in industrial production and 0.05 units change in consumer prices in the Indian economy. However, this ability gets seriously hampered during the higher oil variance regime in the wake of increasing uncertainly levels. The magnitude of responses also decreases in the second regime. Consequently, we gather an overall positive relationship between crude prices and industrial production in the second regime thereby highlighting greater role of fiscal and monetary initiatives in channelizing industrial production and overall consumer prices in India. There are possibly two different ways to establish relationship between oil price shocks and the underlying variables: theoretical approaches (Brown \& Yucel [4]) and statistical approaches. Statistically, there are further two diverse approaches used over a period of time to account for these linkages. First relates to studies capturing impact of specific oil price shocks on macroeconomic fluctuations (Ji et al. [48]) and second relates to asymmetric response of these variables toward oil price shocks separately during positive or negative oil price changes (Donayre \& Wilmot [49]). Theoretically, an oil price shock may derail industrial production and consumer prices in an economy from their conventional trends. However, there are various other factors, for instance availability of oil subsidies, policy response of monetary and fiscal authorities, contribution of crude in overall energy consumption, state of crude oil variance, capacity constraints during high oil volatility regimes, indirect taxes and so on that may counterfeit the impact of such oil price shocks. Out of these, the present study intended to capture these dynamic asymmetric interactions between oil price shocks and Indian macroeconomic variables during both higher and lower oil price volatility regimes. Talking about effects of oil prices on economic activities, Brown and Yucel [4] advocated four general categories, namely reduction in supply of the input decreasing the output, income transfer effect from oil importing country to the oil exporting ones, real balance effect, and lastly monetary policy effect causing significant effects on economic activities. All these effects basically pertain to some kind of impact on domestic economic activities through diverse channels. Our findings also report dynamic interactions between undertaken macroeconomic variables and crude oil shocks. The findings bear strong implications for the policy makers to effectively manage macroeconomic stability during volatile oil price phases.

\section{Concluding Remarks}

The present study attempted to understand asymmetric dynamic interactions between global crude oil price shocks and Indian macroeconomic variables by 
employing MS-VAR regime-dependent impulse responses in level forms. The findings hold an important place in the wake of inflation targeting regime adopted by the monetary policy authorities. In this regime, movements of consumer prices are tracked out with much more prudence in order to keep the latter prices at a subdued level. Industrial production also bears a strong relationship with the crude prices. The findings highlight existence of two regimes, namely lower and higher oil price variance regime. In the lower oil variance regime, there is negative (positive) relationship observed between crude oil shocks and industrial production (consumer prices). The latter relationship is theoretically consistent on account of lesser degree of uncertainty in the movement of crude prices. On the other hand, in the higher oil variance regime, both industrial production and consumer prices are exhibiting a positive relationship with crude oil shocks causing cost pushed inflation. Perhaps, there is an equilibrium shift in the industrial production in the long run in India. This relationship naturally highlights the importance of oil subsidies and certain supply side constraints entailing to an equilibrium shift in the Indian industrial production. The consumer prices are expectedly following an increasing trend in the higher oil price variance regime. A higher degree of volatility causes greater uncertainty around movement of crude oil prices thereby spotlighting the imperative role of other fiscal and monetary economic factors to support consumer demand and industrial production. The findings bear strong implication for the policy makers in their attempt to combat effects of crude oil shocks. As per the findings, the emerging market policy makers should display a cautious approach during higher oil price volatile phases in order to support industrial production and consumer demand.

\section{References}

[1] Hamilton, J.D. (1983) Oil and the Macroeconomy since World War II. Journal of Political Economy, 9, 228-248. https://doi.org/10.1086/261140

[2] Hamilton, J.D. (1996) This Is What Happened to the Oil Price-Macroeconomy Relationship. Journal of Monetary Economics, 38, 215-220.

[3] Hamilton, J.D. (2003) What Is an Oil Shock? Journal of econometrics, 113, 363-398.

[4] Brown, S. and Yucel, M. (2002) Energy Prices and Aggregate Economic Activity: An Interpretative Survey. Quarterly Review of Economics and Finance, 42, 193-208.

[5] Kilian, L. (2008) The Economic Effects of Energy Price Shocks. Journal of Economic Literature, 46, 871-909. https://doi.org/10.1257/jel.46.4.871

[6] Hamilton, J.D. (2008) Understanding Crude Oil Prices (w14492). National Bureau of Economic Research. https://doi.org/10.3386/w14492

[7] Elder, J. and Serletis, A. (2010) Oil Price Uncertainty. Journal of Money, Credit and Banking, 42, 1137-1159. https://doi.org/10.1111/j.1538-4616.2010.00323.x

[8] Jo, S. (2014) The Effects of Oil Price Uncertainty on Global Real Economic Activity. Journal of Money, Credit and Banking, 46, 1113-1135. https://doi.org/10.1111/jmcb.12135

[9] Kesicki, F. (2010) The Third Oil Price Surge-What's Different This Time? Energy Policy, 38, 1596-1606. 
[10] Mork, K.A. (1994) Business Cycles and the Oil Market. The Energy Journal, 15, 15-38.

[11] Lardic, S. and Mignon, V. (2008) Oil Prices and Economic Activity: An Asymmetric Cointegration Approach. Energy Economics, 30, 847-855.

[12] Hanson, K., Robinson, S. and Schluter, G. (1993) Sectoral Effects of a World Oil Price Shock: Economy Wide Linkages to the Agricultural Sector. Journal of Agricultural and Resource Economics, 18, 96-116.

[13] Granger, C.W.J. (1996) Can We Improve the Perceived Quality of Economic Forecasts? Journal of Applied Econometrics, 11, 455-473. https://doi.org/10.1002/(SICI)1099-1255(199609)11:5<455::AID-JAE408>3.0.CO;2$\underline{\mathrm{E}}$

[14] Perron, P. (2006) Dealing with Structural Breaks. Palgrave Handbook of Econometrics, 1, 278-352.

[15] Hamilton, J.D. and Susmel, R. (1994) Autoregressive Conditional Heteroskedasticity and Changes in Regime. Journal of Econometrics, 64, 307-333.

[16] Krolzig, H.M. (2001) Markov-Switching Procedures for Dating the Euro-Zone Business Cycle. Vierteljahrshefte zur Wirtschaftsforschung, 70, 339-351. https://doi.org/10.3790/vjh.70.3.339

[17] Clements, M.P. and Krolzig, H.M. (2002) Can Oil Shocks Explain Asymmetries in the US Business Cycle? In: Hamilton, J.D. and Raj, B., Eds., Advances in MarkovSwitching Models. Applications in Business Cycle Research and Finance, PhysicaVerlag, 41-60.

[18] Singh, A. and Singh, M. (2016) Risk-Return Relationship in BRIC Equity Markets: Evidence from Markov Regime Switching Model with Time-Varying Transition Probabilities. Metamorphosis: A Journal of Management Research, 15, 69-78.

[19] Burbidge, J. and Harrison, A. (1984) Testing for the Effects of Oil-Price Rises Using Vector Autoregressions. International Economic Review, 25, 459-484. https://doi.org/10.2307/2526209

[20] Loungani, P. (1986) Oil Price Shocks and the Dispersion Hypothesis. The Review of Economics and Statistics, 68, 536-539. https://doi.org/10.2307/1926035

[21] Gisser, M. and Goodwin, T.H. (1986) Crude Oil and the Macroeconomy: Tests of Some Popular Notions: Note. Journal of Money, Credit and Banking, 18, 95-103. https://doi.org/10.2307/1992323

[22] Mork, K.A. (1989) Oil and the Macroeconomy When Prices Go Up and Down: An Extension of Hamilton's Results. Journal of Political Economy, 91, 740-744. https://doi.org/10.1086/261625

[23] Rotemberg, J.J. and Woodford, M. (1996) Imperfect Competition and the Effects of Energy Price Increases on Economic Activity [Working w5634]. National Bureau of Economic Research.

[24] Cunado, J. and Gracia, F.P.D. (2005) Oil Prices, Economic Activity and Inflation: Evidence for Some Asian Countries. The Quarterly Review of Economics and Finance, 45, 65-83.

[25] Bachmeier, L. (2008) Monetary Policy and the Transmission of Oil Shocks. Journal of Macroeconomics, 30, 1738-1755.

[26] De Gregorio, J., Landerretche, O., Neilson, C., Broda, C. and Rigobon, R. (2007) Another Pass-Through Bites the Dust? Oil Prices and Inflation. Economia, 7, 155208. https://doi.org/10.1353/eco.2007.0014

[27] Zhang, Q. and Reed, M. (2008) Examining the Impact of the World Crude Oil Price on China's Agricultural Commodity Prices: The Case of Corn, Soybean, and Pork. The Southern Agricultural Economics Association Annual Meetings, 5, 2008. 
[28] Chen, S.S. (2010) Do Higher Oil Prices Push the Stock Market into Bear Territory? Energy Economics, 32, 490-495.

[29] Sims, C. (1980) Macroeconomics and Reality. Econometrica, 48, 1-48. https://doi.org/10.2307/1912017

[30] LeBlanc, M. and Chinn, M.D. (2004) Do High Oil Prices Presage Inflation? The Evidence from G-5 Countries. UC Santa Cruz Economics [Working Paper 561], SCCIE.

[31] Finn, M.G. (2000) Perfect Competition and the Effects of Energy Price Increases on Economic Activity. Journal of Money, Credit and Banking, 32, 400-416. https://doi.org/10.2307/2601172

[32] Hooker, M.A. (2002) Are Oil Shocks Inflationary? Asymmetric and Nonlinear Specifications versus Changes in Regime. Journal of Money, Credit and Banking, 34, 540-561. https://doi.org/10.1353/mcb.2002.0041

[33] Barsky, R.B. and Kilian, L. (2004) Oil and the Macroeconomy since the 1970s. The Journal of Economic Perspectives, 18, 115-134. https://doi.org/10.1257/0895330042632708

[34] Zhang, D. (2008) Oil Shock and Economic Growth in Japan: A Nonlinear Approach. Energy Economics, 30, 2374-2390.

[35] Jiménez-Rodríguez, R. and Sánchez, M. (2012) Oil Price Shocks and Japanese Macroeconomic Developments. Asian-Pacific Economic Literature, 26, 69-83. https://doi.org/10.1111/j.1467-8411.2012.01336.x

[36] Abeysinghe, T. (2001) Estimation of Direct and Indirect Impact of Oil Price on Growth. Economics Letters, 73, 147-153.

[37] Ran, J. and Voon, J.P. (2012) Does Oil Price Shock Affect Small Open Economies? Evidence from Hong Kong, Singapore, South Korea and Taiwan. Applied Economics Letters, 19, 1599-1602. https://doi.org/10.1080/13504851.2011.641924

[38] Kapur, M. (2013) Revisiting the Phillips Curve for India and Inflation Forecasting. Journal of Asian Economics, 25, 17-27.

[39] Mohanty, D. and John, J. (2015) Determinants of Inflation in India. Journal of Asian Economics, 36, 86-96.

[40] Davis, S.J. and Haltiwanger, J. (2001) Sectoral Job Creation and Destruction Responses to Oil Price Changes. Journal of Monetary Economics, 48, 465-512.

[41] Hamilton, J.D. and Herrera, M.A. (2002) Oil Shocks and Aggregate Macroeconomic Behavior. Journal of Money, Credit and Banking, 36, 265-286. https://doi.org/10.1353/mcb.2004.0012

[42] Ehrmann, M., Ellison, M. and Valla, N. (2003) Regime-Dependent Impulse Response Functions in a Markov-Switching Vector Autoregression Model. Economics Letters, 78, 295-299.

[43] Balcilar, M., Gupta, R. and Miller, S.M. (2015) Regime Switching Model of US Crude Oil And Stock Market Prices: 1859 to 2013. Energy Economics, 49, 317-327.

[44] Hamilton, J.D. (1990) Analysis of Time Series Subject to Changes in Regime. Journal of Econometrics, 45, 39-70.

[45] Krolzig, H.M. (1997) Markov Switching Vector Autoregressions Modelling: Statistical Inference and Application to Business Cycle Analysis. Springer, Berlin. https://doi.org/10.1007/978-3-642-51684-9

[46] Sims, C., Stock, J.H. and Watson, M.M. (1990) Inference in Linear Time Series Models with Some Unit Roots. Econometrica, 58, 113-144.

https://doi.org/10.2307/2938337 
[47] Davies, R.B. (1987) Hypothesis Testing When a Nuisance Parameter Is Present only under the Alternative. Biometrika, 74, 33-43.

https://doi.org/10.1093/biomet/74.1.33

[48] Ji, Q., Liu, M. and Fan, Y. (2015) Effects of Structural Oil Shockson Output, Exchange Rate, and Inflation in the BRICS Countries: A Structural Vector Autoregression Approach. Emerging Markets Finance and Trade, 51, 1129-1140. https://doi.org/10.1080/1540496X.2015.1080505

[49] Donayre, L. and Wilmot, N.A. (2016) The Asymmetric Effects of Oil Price Shocks on the Canadian Economy. International Journal of Energy Economics and Policy, 6, 167-182.

Submit or recommend next manuscript to SCIRP and we will provide best service for you:

Accepting pre-submission inquiries through Email, Facebook, LinkedIn, Twitter, etc. A wide selection of journals (inclusive of 9 subjects, more than 200 journals)

Providing 24-hour high-quality service

User-friendly online submission system

Fair and swift peer-review system

Efficient typesetting and proofreading procedure

Display of the result of downloads and visits, as well as the number of cited articles Maximum dissemination of your research work

Submit your manuscript at: http://papersubmission.scirp.org/

Or contact tel@scirp.org 